\title{
The mechanical behaviour of frozen earth materials under high pressure triaxial test conditions
}

\author{
CHAMBERlaiN, E., GROVES, C. and PERHAM, R. (1972). Geotechnique 22, No. 3, 469-483.
}

\section{O. B. Andersland, Michigan State University and Bernard D. Alkire, Michigan Technological University}

The Authors are to be commended for their work on a difficult experimental problem and the useful data which have been derived therefrom. Some additional work at Michigan State University supports their results and appears to provide some insight concerning unanswered questions in the low stress region. All samples tested by the Authors were ice-saturated which served to emphasize the influence of pressure melting and ice-water phase transition on the mechanical behaviour of the frozen soil. The other extreme would be dry samples which should give a behaviour similar to unfrozen soils under high pressures.

Data showing the influence of confining pressure and an intermediate degree of ice saturation on peak deviator stress for 20-30 Ottawa sand are given in Fig. 1. A uniform increase in peak deviator stress, regardless of the confining pressure, shows that the change in strength is primarily because of an increase in ice content. Pressure melting appears to have a negligible effect for confining pressures of $700 \mathrm{lb} / \mathrm{sq}$. in. since the increase in peak deviator stress was the same for the two values of ice saturation. The significance of this data becomes more apparent when maximum principal stress ratio is plotted against confining pressure for the three levels of ice saturation shown in Fig. 2. Comparisons with data for the unfrozen Ottawa sand show that the cohesive component because of the ice becomes very small at confining pressures approaching $1000 \mathrm{lb} / \mathrm{sq}$. in. This would suggest that at stresses greater than $1 \mathrm{kip} / \mathrm{sq}$. in. the shear strength

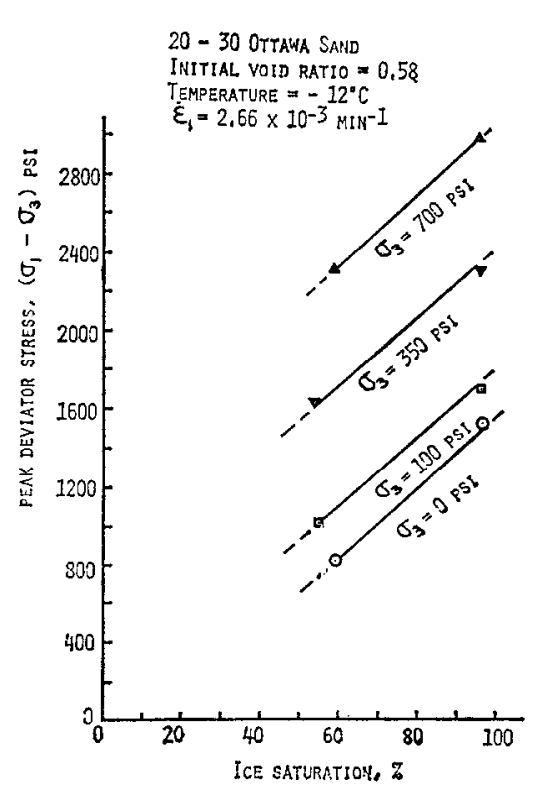

Fig. 1. Relationship between deviator stress at failure and ice saturation for Ottawa sand at four levels of confining pressure

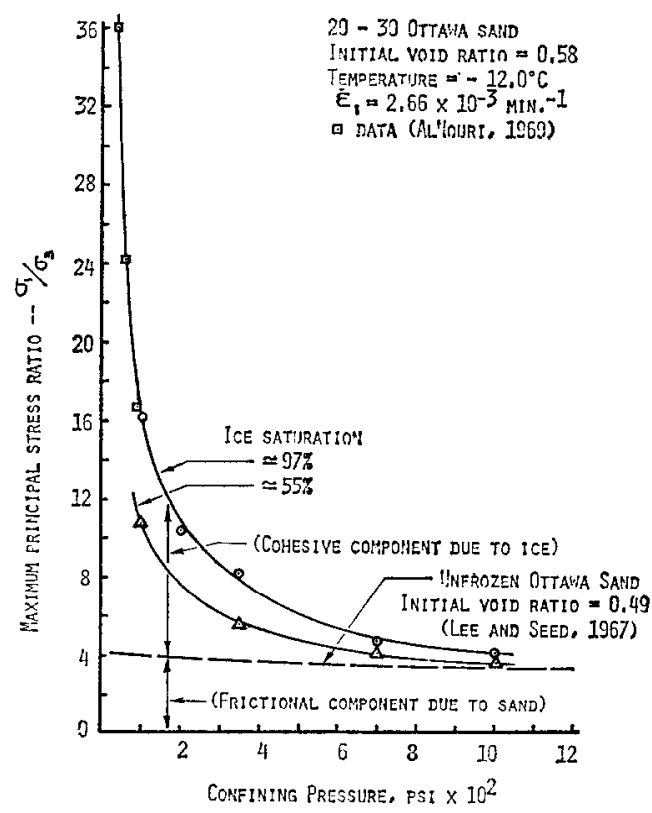

Fig. 2. Relationship between principal stress ratio at failure and confining pressure for Ottawa sand at three levels of ice saturation 
is primarily because of sliding friction, particle crushing and rearranging effects. Dilatancy has been suppressed for the higher pressures.

The decrease in strength observed for the mid-pressure region may be because of a build-up of excess pore pressures brought on by pressure melting and ice-water phase transition. Effective stresses would be reduced since drainage was impossible for the test conditions imposed on the frozen sample.

For the high pressure region greater compressibility of the pore water compared with the solids may again allow a slow increase in the frictional component of shear strength with increase in pressure. Skempton and Bishop (1954) stated that the cubical compressibility of soil grains is of the order $1 \times 10^{-7}-2 \times 10^{-7}$ per lb/sq. in. compared with that of water which is $3.4 \times 10^{-6}$ per $\mathrm{lb} / \mathrm{sq}$. in. This difference would allow a small increase in effective stress with increase in pressure. For soil samples with lower degrees of ice and water saturation the shear strength would be modified with the extreme behaviour characterized by dry samples.

\section{REFERENCES}

Alkire, B. D. (1972). Mechanical properties of sand-ice materials. Ph.D. thesis, Michigan State University. AlNouri, I. (1969). Time dependent strength behaviour of two soil types at lowered temperatures. Ph.D. thesis, Michigan State University.

Lee, K. L. and Seed, H. B. (1967). Drained strength characteristics of sands. Jnl Soil Mech. Fdns Div. Am. Soc. Civ. Engrs 93, SM6, 117-141.

Skempton, A. W. \& Bishop, A. W. (1954). Soils in building materials, their elasticity and inelasticity (ed. by M. Reiner) chap. 10. New York: Interscience Publishers, Inc.

\section{A note on a plasticity solution to the stability of slopes in inhomogenous clays}

BOOKER, J. R. and DAVIS, E. H. (1972). Géotechnique 22, No. 3, 509-513.

\section{J. Endicott, G. Maunsell and Partners}

The Authors have obtained analytical solutions for slopes under conditions of plane strain in a cohesive material where the strength of the material is proportional to depth and is zero at the top horizontal surface of the slope.

The plasticity analysis can be readily extended to cater for a more general inhomogeneity in strength. Adopting the notation used by the Authors, suppose that the shear strength $c$ is a function of both co-ordinates, $x$ and $z$, and that the body force $\gamma$ has components $\gamma_{x}$ and $\gamma_{z}$, not necessarily constant, in the $x$ and $z$ directions. Variations in $\gamma$ do occur, for instance within a model being tested on a centrifuge.

When $c, \gamma_{x}$ and $\gamma_{z}$ are continuous functions, the Authors' equations (1)-(3) become

$$
\begin{aligned}
& \frac{\mathrm{d} x}{\mathrm{~d} z}=\tan \left(\theta \pm \frac{\pi}{4}\right) \\
& \mathrm{d} p+2 c \mathrm{~d} \theta=\left(\gamma_{z}+\frac{\mathrm{d} c}{\mathrm{~d} x}\right) \mathrm{d} z+\left(\gamma_{x}-\frac{\mathrm{d} c}{\mathrm{~d} z}\right) \mathrm{d} x \text { along an } s_{1} \text { line } \quad . \quad \text {. } \\
& \mathrm{d} p-2 c \mathrm{~d} \theta=\left(\gamma_{z}-\frac{\mathrm{d} c}{\mathrm{~d} x}\right) \mathrm{d} z+\left(\gamma_{z}+\frac{\mathrm{d} c}{\mathrm{~d} z}\right) \mathrm{d} x \text { along an } s_{2} \text { line } \quad \text {. }
\end{aligned}
$$

Inspecting these equations for the conditions when $c=\rho z, \gamma_{x}=0, \gamma_{z}=\gamma$ with $\rho, \gamma$ constant yields the Author's equations (1)-(3)

In order to obtain a solution to equations (1)-(3), the Writer used a numerical method of integrating along the $s_{1}$ and $s_{2}$ lines (Endicott, 1970). This method of solution allows a 